\title{
Exploring Relations to Documents and Documentary Infrastructures: The Case of Museum Management After Austerity
}

Bethany Rex*

\begin{abstract}
Interaction with documents and documentary infrastructure is part of the day to day reality of museum work. However, their constitutive and mediatory role is rarely foregrounded in empirical studies of museums. In part, this is because a defined theoretical and methodological framework for such an investigation has yet to be developed. This article outlines what a conceptualization of documents as morethan-text informed by actor-network theory offers to studies of museums, particularly the potential of this method for investigating how documentary infrastructures influence daily practice and inform notions of possible action amongst museum staff. The insight that institutional practices operate 'on the field of possibilities' is Foucault's ([1982] 2000: 341). However, as I outline in this article, actor-network theory took up this insight and developed it, drawing out its methodological and analytical consequences. Empirical material exploring the influence of Arts Council England's Accreditation Scheme on someone new to museum work, drawn from a study of community asset transfer, a process whereby people new to museum work become responsible for the operation and management of museums previously run by local authorities, is used to demonstrate the potential of this approach. ${ }^{1}$
\end{abstract}

Key words: Community asset transfer, expertise, actor-network theory, organizational culture, methodologies, documents

\section{Introduction}

Documents are ubiquitous in the modern workplace and museums are no exception. They play an important role in structuring workplace routines and occupy a significant proportion of worktime, yet are currently under-researched. Against the view that documents are an adjunct to museum work, the central argument of this article is that museum work is mediated by the documents and documentary infrastructures that partly constitute it. As I go on to suggest, certain methodological frameworks are better suited for exploring the constitutive function of documents and documentary infrastructures and the part they play in shaping museum practice. In outlining one such framework, my intention is to emphasize the question of the document's role as an empirical one, and to encourage further work concerning this aspect of museums.

The use of empirical methodologies to elicit descriptions of practice are commonplace in museum and heritage studies, yet the processes, materials and procedures encountered during that practice are often invisible in such accounts. As Conal McCarthy observes in his introduction to the 2015 publication, Museum Practice, this is, in part, due to a divide between 'what actually goes on in museum work' (xxxv) and the dominant readings of museums that circulate in museum studies where a view of 'how things happen' has been slow to emerge. This gap is partly addressed in contemporary work centred on practice, oftentimes written by practitioners themselves (e.g. Gardner 2015), where recent contributions have provided detailed accounts of what happens in museums, situating practice in its institutional, political, economic and historical contexts. However, perhaps because of the perceived need to offer descriptive accounts informed by personal experience, there remains scope to consider how the 'detailed empirical picture of the contemporary museum' desired by several scholars (McCarthy 2015; 
Shelton 2015) can incorporate critical analysis. This is necessary, as this paper will demonstrate, because museum practice is shaped by specific texts, bodies and infrastructures unaccounted for by umbrella terms such as 'power relations' or 'context'. Documents and documentary infrastructure are one of the features of museum practice elided in current accounts, particularly how they shape the inner workings of museums. On these grounds, this paper illustrates the potential of theoretically-informed methods to produce nuanced pictures of contemporary museum practice that retain an analytical edge. As several authors have acknowledged, we cannot ignore how museums function to focus solely on how their representations are perceived (Macdonald 2006: 8-9; Mason 2006: 29-30). In foregrounding how museum work proceeds we must also recognize the influence of the 'how' on the 'what'. Practices and procedures are not neutral: they carry in-built assumptions and contain within them the potential to work on the world. The methodological approach outlined in this article aims to render visible the networks of connection and association out of which museum practice, and perceptions of its possibilities, take shape and are sustained.

This focus of this article is to provide a theoretical and methodological framework to support further empirical work in this vein, and to present an example of an encounter between Arts Council England's Accreditation Scheme (herewith Accreditation) to illustrate the value of this approach, particularly its implications for conceptualizations of expertize in museums and heritage debates. The sustained focus on theory in this article is informed by an underlying argument that theory be used to inform methodological frameworks rather than as an interpretative tool for empirical material already collected. In so doing, this article responds to the special issue's intention to develop methods suited to the organizational or bureaucratic character of museums, as well as to a broader call within museum and heritage studies to make our means transparent (Sørensen and Carman 2009: 3-11) whilst also investigating the multidimensionality of the myriad practices involved in museum and heritage work (Jones and Yarrow 2013).

My focus on documentary infrastructures is informed by current scholarship in the field of museum and heritage studies where an anatomic view of museums has produced detailed accounts of their inner workings. Sharon Macdonald's Behind the Scenes at the Science Museum (2002) is an important text in this regard, bringing into focus how decisions about exhibitions are made and the logics underpinning the various choices involved in producing museum displays (see also Yaneva 2003; Waller 2016; Patrick 2016). Uniting this literature is an ambition to lift the processes involved in museum work from obscurity, contributing important insights on how aspects of museums which are frequently viewed as settled and selfevident are in fact the result of compromises and negotiations wherein issues of professional expertize and political agendas play a central role. Museum collections are an ideal subject for such an analysis, with assemblage theory providing the basis for 'unpacking' their coming together as an outcome of processes imbued with social, historical and political nuance and that extend beyond the museum (e.g. Gosden and Larson 2007; Larson et al. 2007; Bennett 2010; Bryne et al. 2011). Other studies, although they have their own points of interest, have taken up this call to address the finer details of: museum work (e.g. Geohegan and Hess 2015 on curators); forms of museum practice (e.g. Knudson 2016 on participation) and the stuff that museums are made of (e.g. Graham 2016 on display apparatus). However, while this new wave of scholarship tells a story of composition, providing an important addition to questions of representations and their reception by visitors, current scholarship has shown less interest in what can be thought of as the prosaic day-to-day features of museum practice. The idea of the museum-as-organization is instructive here, as it encourages an un-romantic approach to the museum wherein collections, displays and their construction are set aside in favour of an alternative point of departure. Viewing museums not so much as occupying a distinctive place in the public imagination, but as no different to other types of modern organization in that they are sustained through routine procedure and practices, is vital if we are to grasp the heterogeneous elements that make up museums.

Documents and documentary infrastructures have not been entirely overlooked in studies of museums, yet a textual view of documents takes precedence over the practice orientated view advanced here. Instead of reading documents for what they say, my concern is to emphasize what they do and what emerges from interactions between people and the 
documents and documentary infrastructures they encounter in their work worlds. As Susan Leigh Star observes, organizations are undergirded by 'unstudied infrastructure that permeates all its functions' with technical aspects carrying with them the outcomes of decisions and values (1999: 379). This stance is a mechanism for rewinding from representations to habitual practices that may have their origins in spaces other than the museum, with Accreditation providing a case study for this argument. My argument, however, is not that documents be included in empirical studies of museums because they are currently missing, but because of the important work these things do in and on the museum. In this article, documentary infrastructures refers to mechanisms that regulate museum practice (e.g. professional standards, ethical codes and policy frameworks) whilst documents refers to the vast range of written outputs produced within museums and beyond.

I begin by positioning actor-network theory as a development of Michel Foucault's composite view of power, drawing on Tony Bennett's work where the connections between these lines of thinking and their implications for museum studies has been most fully elaborated. Here, I argue that there is latent potential for these ideas to be put to further use, particularly to inform studies of professional practice, as it can be viewed as subject to government in much the same way as Bennett's publics are (2005). Second, John Law's 'relational materialism' is offered as means into such a study, namely for the stress it places on influence and ordering power as a relational, provisional and emergent property. These theoretical propositions are examined via the case study of Accreditation. Through presenting an example of the interplay between documentary infrastructure and people in a specific setting my purpose is to demonstrate the broader applicability of this approach and its implications for how the constitution and effects of expertize are examined in the field.

\section{Foucault and Actor-Network Theory}

Power, understood as a set of practices wherein the material and 'non-social' are held to play a constitutive role is foundational to actor-network theory (Latour 2005: 1-4). Foucault's (1980) theorization of the mutually reinforcing relation of knowledge practices and power structures is a foundational precursor to this line of enquiry. Yet, whereas the conceptual framework was laid out by Foucault, actor-network theory clarifies its consequences for methodology. Bennett highlights the potential of actor-network theory as an expansion of Foucauldian ideas into empirically grounded accounts of how power operates and with what effects:

There is, as Law notes, a good deal of common ground here between ANT and those readings of Foucault's concept of discourse which stress its material and institutional properties. But there is, he argues, also a difference to the extent that ANT places a greater stress on analysing the processes through which things are put together to form, and re-form, those ordering strategies that Foucauldian analysis calls discursive but whose formation - the processes of their making and remaking - it tends to occlude (2007: 614-615, citing Law 1994: 18-26).

Bennett draws on these ideas across a number of his contributions as a means to fuller description of how museums bring 'objects together in new configurations, making new realities and relationships both thinkable and perceptible' (2005: 7; 2007; 2013a; 2013b; Bennett and Joyce 2010). The relationship between museums and institutions orientated towards social intervention is crucial for Bennett, as it is this that makes what is thinkable and perceptible also actionable. For example, Baldwin Spencer's typological displays and the idea of sequenced evolutionary development were later drawn upon during the development of social programmes premised on normative notions of 'Aboriginality' first fabricated in the museum. The question of how knowledge practices establish the grounds for governmental projects could be analyzed through a purely Foucauldian frame. However, the analytical purchase of actor-network theory is its attention to the granular detail of how new knowledge realities are established in practice and the combination of elements involved, particularly evident in Making Culture, Changing Society (Bennett 2013a) where these minutiae are presented in full. Here, a phased account of the assembly and exhibition of artefacts collected by Spencer is expanded to detail the circumstances affording the anthropologist who would later foray into the work of government 
the capacity to bring items of 'material culture' into the National Museum of Victoria. Further, Bennett illustrates how specific communication methods were employed by Spencer to legitimize the authority of his ethnographic texts, laying the grounds for a positive reception of those ideas which he later drew upon in his governmental projects (in both senses of the word).

Bennett's dialogue with actor-network theory affords an analysis which simultaneously zooms in on the museum, in that it acknowledges the many more things present therein, and zooms out from it as a means to re-visioning museums and their knowledge practices as implicated in power relations beyond exhibition spaces. However, as Bennett has developed the ideas of actor-network theory within the context of his own intellectual project, there is scope to further mobilize these insights for museum studies. In order to do so, three moves are necessary.

The first move concerns the type of materials made visible via empirical work. Bennett's identification of administrative procedures and other material forms as part of the mechanisms of governmental power informs a discussion of how museums produce knowledge by manipulating 'relations between people and things in a custom-built environment'(Bennett 2005: 6). Attention is paid to techniques of display, collecting practices and the contributions of museum staff, aspects that we might anticipate to be relevant to museums. A similar inclination to the conventionally museological means work in museum anthropology has concentrated on cataloguing and documentation practices (Turner 2016). There is scope, therefore, to look again at museums to investigate other texts, practices and infrastructures which may configure museum practice in different ways. Bennett acknowledges this himself, yet still frames his argument within an interest in how collections are formed and displayed (Bennett 2015: 12; 2013b).

The 'minimal conception of agency' forwarded by actor-network theory (Sayes 2014: 141 ) is helpful here as it provides the grounds for empirical investigations to take an interest in all forms that configure museum practice in significant ways. Accreditation is but one example of this approach; other topics could include ethics policy (Marstine et al. 2013), past and present mission statements or the strategic plans of local authorities.

The second move concerns what Helen Graham has identified as 'interpretive distance' (2012: 568). Using this term to highlight the implications of Bennett's reading of museums as objects of government for how we approach museums as an object of study, she argues that while museums are implicated in governmental projects directed towards reform, this is not an adequate description of the relations and effects that museums give rise to.

The crucial point she makes relates to methodologies. It is not that Graham disputes Bennett's rendering of museums as a form of governmental power, rather that this reading designates and delimits the purpose of museums in a way that risks foreclosing the possibility of interpretations other than the top-down view of how power operates in and through the museum (Graham 2012: 569). This encourages a two-pronged short circuit. Analytically, variability is downplayed to make space for commentary on the museum's political rationalities, pulling contemporary practices back from their possibilities by locating them firmly within the logics present at the inception of 'all' museums. Methodologically, distance from practice is promoted by the suggestion that the end-goals of museums can be fixed within this governmental logic, encouraging interpretations of museums to take place at a certain distance from where such a view can be upheld.

The upshot of Graham's observations is for research to consider museums of different types, engaging in different forms of what can appear as the same practice in order to make the variability of intentions and effects visible. This is crucial if the methodological framework outlined in this article is to have purchase in practice on the grounds that interpretive orientations shape what there is to know, and are implicated in casting the world in a particular light. That is to say, where we fix our eyes, for how long, and the tools and vocabularies we carry with us during this process - and the implications of this for the contributions elicited from participants - is an act of 'making something present by making absence' (Law 2004: 144). The methodological framework advanced here is designed to attend to the effects of documentary infrastructures and, in so doing, it suppresses other factors also present. The proximity to practice, both as a description of the positionality of the researcher and the ends towards which research tools such as interviewing are directed, makes other ways of knowing museums possible.

The third move relates to the relative openness of research towards the effects arising 
from encounters between persons and things. Several authors, including Bennett, consider how objects are pieced together as collections, installed into museum environments by curatorial practices which construct 'new cultural knowledges' (2007: 618) or 'surfaces' (2013a: 82), which then intersect with other objects of government (e.g. education) to further legitimize social programmes and produce further effects on populations. There are, however, a greater number of effects beyond the construction of knowledge for the purposes just described taking place in the museum which do not relate to exhibitions, a point Bennett makes himself in a discussion of the advantages of approaches that attend to the unpredictable relations between 'texts, things, technologies, and bodies that museums orchestrate' whilst, as a corollary, allowing for 'greater variability in the fields of effect to which this gives rise' $(2015: 15) .{ }^{2}$ On these grounds, documentary infrastructures and persons need to be seen as being brought together in manifold ways with unpredictable effects. The concept of 'relational materialism', developed by John Law $(1992 ; 1994 ; 1999 ; 2004)$ is well-suited to bringing these dynamics to the fore.

\section{Beyond a textual emphasis via 'relational materialism'}

When approached as text, the implication is that documents are 'inert carriers of content' (Prior 2008: 823) existing at a level separate from the bodies and practices taking place in museums or heritage sites. This is particularly apparent in studies of cultural policy (cf. McCall 2016). Here, several studies examine what is written about the role and purpose of museums at the level of official cultural policy. For example, in Culture, Economy and Politics: The Case of New Labour (2015) Hesmondhalgh and colleagues undertake an expansive reading of policy documents (supplemented with interviews) to assess macro changes to cultural policy during the New Labour administration (1997-2010), a period during which conceptions of culture and understandings of its purpose underwent significant change. Writing in an Australian context, yet maintaining a focus on the textual, McShane reads a prioritization of productive forms of culture in key national policy texts (2016). Relatedly, Mason's analysis of the competing discourses of 'social inclusion' acknowledges the role of governmental framings (expressed through policy and in statements to the media) as well as the contribution of museological projects and statements of intent arising from the museum sector itself (2004). This work is important as an assessment of how organizational and political positions change over time. However, a reliance on formal documentation, plus a tendency to view these documents solely as representations of human beliefs or ideology, overlooks, as Prior puts it, how 'documents function in the everyday world' (2008: 824) and how they came to be there in the first place.

The 'relational materialism' associated with Law $(1992 ; 1994 ; 1999 ; 2004)$ is a useful corrective to these approaches, for its emphasis on agency as an interactional effect. Whilst this statement is typical of actor-network theory, Law's 'relational materialism' is a useful term to think with because it is a buttress against arguments that mistake the proposition that materials shape action as a deterministic view (e.g. Knell 2012). To foreground the material, and the interplay between materials, persons, texts, environments and so forth, is not to claim that entities have innate power to shape and influence action or understanding, but to attend to their capacity as an effect of the associations of which an object is part (Sayes 2014). There is nothing inherent or pre-given about the agentive capacity of documentary infrastructures for, even when they have become part of the furniture of a particular domain of practice, their ability to shape and mediate is always an outcome of the type of relations that exist between it and other entities. Further, these relations are not all of the same type, as the relation between one entity and another may be one of instruction or choice.

The upshot of this inherent relationality is that enquiring into documents is not about infusing a document or documentary practice with casual properties in and of itself. It is always about understanding the role said document plays in relation to other people and things. Rather than providing a bird's eye view of documents in the museum sector, an inquiry based on these frameworks is interested in local circumstance and specificity so is required to be 'empirical through and through' (Latour 1986a: 3) in order to trace the precise effects documentary infrastructures have on specific settings.

As far as these effects are concerned, the point is to understand the multiple types of relations we can have with documents. As the capacity of the document to make a difference to 
action is not inherent, and cannot be determined in advance, this means the way an encounter with a document acts upon the action of others (Foucault 1980: 340) needs to be understood as a point on a continuum rather than an either/or. Latour provides an instructively expansive list of the heterogeneous ways documents may link up with organizational actors:

In addition to 'determining' and serving as a 'backdrop for human action', things might authorize, allow, afford, encourage, permit, suggest, influence, block, render possible, forbid, and so on (2005: 72).

The multiplicity of modes of relation when encountering documents introduces valuable specificity, yet it remains up to the researcher to select which documents to foreground if their task is to inquire into documents which remain invisible yet are productive of significant effects on 'local processes of patterning, social orchestration, ordering and resistance'(Law 1992: 386). Furthermore, an approach orientated towards documents and documentary infrastructures can focus on the relations involved in a documents' creation or the way it is subsequently encountered in practice. Before turning to Accreditation as a case study of this second approach, I review these two approaches to documents to make the scope of this framing clear.

\section{The production of documents and their performative effects}

Museum work is no different from other forms of contemporary work in that the production of documents is a task occupying a substantial portion of work time.

To study the social production of documents is to study modern knowledge practices (Riles 2006). Situating a document within its trajectory is a way to uncover the negotiations, controversies and compromises which added up to its production, as well as the more basic routines and processes by which documents are produced. Freeman and Maybin make the politics of this process clear, summarizing:

Policy documents, through their writers and editors, may state truths - or they may suppress, elide or embellish them. The process of writing a statement or briefing [or any document], for example, is often a matter of sorting - selecting and ordering - the many truths [or forms of knowledge] it might contain. It matters very much, therefore, just who is allowed or tasked to write what and by whom [and for what purpose] (2011: 161, author's additions in []).

Documents are 'but the fine edge' of a whole series of mobilizations (Latour 1986a: 25) which we can progressively trace by attending to a document's production, a process which involves contexts and actors beyond the text. Questioning a document's production is important because documents are constitutive of the contexts out of which decisions emerge. The document is a gathering together of ideas, information and judgements about possible courses of action around which organizational actors build their subsequent moves.

The question is one of information and its presentation as what is omitted and included functions simultaneously to frame the problem and implies 'appropriate' solutions. But it is not merely the inclusion of information that is relevant, for, as Riles (2006) notes, documents belong to genres and within each genre exists ideas about what a good specimen of that genre looks like. The aesthetic quality of a document elicits a response in the reader, for bullet points, say, create a sense of logic and rationality (see also Latour 1986a) but the aesthetics required by the document also appeal to a particular form of creativity (or lack thereof) on the part of the author (Riles 2006: 19, 21, 194). Further, documents are starting points for future action but also moments of closure, reduction and erasure. In Latour's terms, they are a 'common place for many other inscriptions to come together', with inscriptions for Latour being matter transformed into written forms capable of travelling beyond the contexts of their production (1986a: 25). A document condenses contested information into one 'finished' output and has the effect of flattening out inconsistencies in the information it summarizes. Importantly, then, documents channel decisions rather than expressing decisions made by individuals which are then written up as a document (Freeman and Maybin 2011: 3). Similarly, as documents travel from one context to another, they may be acknowledged or ignored, indicating the value of acknowledging how documents elicit or anticipate certain types of response. The second avenue of inquiry pertaining to documents centres on the responses they elicit. 
As they become part of organizational life, documents can shape interpersonal interactions and lend structure to organizational activities. The degree to which a documentary practice encases organizational activity is defined in relation to the network of which it forms part, and in many cases certain documentary infrastructures may have taken on a foundational character in a network.

Examining the interplay between Accreditation and someone new to museum work provides an example of the way notions of professional practice are partly constituted by documentary infrastructures, an insight that is especially important in the context of museum asset transfer. ${ }^{3}$ This process involves the transfer of responsibility for a museum from a local authority to an external organization, a practice that is part of an 'ongoing trend among local authorities to transfer operations outside council control' (Museums Association 2017: 10). ${ }^{4}$ Extensive cuts to public sector budgets in the UK have given rise to these developments, which are characterized by individuals and groups with little prior experience of museum work assuming responsibility for their future operation as a reaction against proposed closure. $\mathrm{A}$ rhetoric of greater involvement of individuals and groups with an interest in these museums, and their increased agency to determine what these spaces do and who they function for undergirds these developments. As such, how documentary infrastructures inform and limit possible action in these contexts becomes a political matter. The following section draws on multiple interviews with the Chair of a group who became responsible for a small local authority museum in North-West England in 2013. ${ }^{5}$

\section{Professional Standards: Configuring Relationships and Bolstering Expertise}

Arts Council England (ACE) is the main development body for museums in the UK. Its Accreditation Scheme is marketed as a defining 'good practice' and identifying 'agreed standards' (Arts Council England 2014a: 3 ) for the museum and galleries sector. ${ }^{6}$ Accreditation is not a requirement but it is a pre-condition for some funding programmes, and there is an expectation that museums wishing to access long-term support from ACE's museum development network participate in the process. The character of the relationship between Accreditation and museums is, therefore, asymmetrical (Hodder 2014: 19) as an absence of an explicit demand for participation is belied by more subtle forms of influence. The weight of this influence is an effect of circumstance. In this case, maintaining Accreditation was a condition of the lease arrangement between the newly formed Independent Trust and the local authority. Further, the financial constraints enveloping local authority museum services are significant in that museum staff are limited in the support they can offer people coming into museum work, increasing the importance attached to the development support that flows from participation in Accreditation.

Financial constraints limit the amount of support existing museum staff are able to offer to transfer groups, yet Accreditation shapes the nature and scope of this support, as well as playing a role in configuring relationships between professionals and those new to museums, whilst also laying out its own particulars of what is required to be considered as a museum professional. However, as it is less the content of Accreditation and more how it is received in different settings that is of interest, it is necessary to turn to how this influence was described by the interviewee, before returning to a discussion of its specific effects:

When I came into the museum I didn't have enough basic knowledge of what the key concerns of working in a museum were. I have learnt what they are through Accreditation but it's a bit like learning from a textbook and regurgitating it, like you do in exams. (Chair of Independent Museum Trust 2015). ${ }^{7}$

It was just telling us precisely how to do museum work, and, you know, when you're thinking about survival, when you are just trying to keep your head above water, it becomes more about ticking the boxes really. (Chair of Independent Museum Trust 2016). ${ }^{8}$

Discernible in these comments is the authority invested in Accreditation in this instance, and the way it is afforded a foundational role due to the circumstances in which it is encountered. In 
addition, Accreditation configures practice in two main ways that I will outline before clarifying the advantage of the approach for the topic of expertize.

The first concerns its contribution to determining the qualities required such that an individual is granted the status of a 'museum professional'. A requirement of Accreditation is for the museum in question to employ a 'museum professional' or to appoint what is termed a museum mentor to fulfil this role (Arts Council England 2014b: 27). ${ }^{9}$ Accreditation carries its own definition of this term as someone with 'a minimum of five years' experience of working in a museum, with recent experience at curator/manager level' plus a 'relevant or linked qualification' (Arts Council England 2014c: 24). ${ }^{10}$ This content constructs an image of museum work as a profession with established criteria for entry and contributed to the interviewees assessment of their capacity to describe their activities as akin to those of a museum professional:

I'm not a museum person no, no way, far from it! First, I don't have the necessary skills, I've got a reasonable amount of common sense and a feeling for it but I don't have the basic knowledge unfortunately (Chair of Independent Museum Trust 2015). ${ }^{11}$

In this case, then, Accreditation is seen to grant licence to some individuals to the subsequent (self-) exclusion of others. This role is assigned to Accreditation by the user based on the specifics of their circumstances, ensuring that the practical tasks of museum work, a notion determined by Accreditation, continue to be conducted by those licensed as having the necessary knowledge and experience.

The second way Accreditation shapes what happens in the museum relates to the nature and scope of professional support offered by museum mentors. Here, highlighting the gap between intended and actual outcome is important as Accreditation organizes behaviour in a way unlikely to bear any resemblance to the effect envisaged by ACE staff. The idea of box-ticking encapsulates the way Accreditation focuses the work pattern of the museum professional in one direction to the exclusion of alternatives. On a regular yet infrequent basis, the authorized professional comes into the museum to undertake environmental monitoring and pest management. The routine performance of tasks to ensure the preservation of appropriate conditions contributes to the instantiation of a caricatured image of museum work. Again, this would appear to further support the notion of professional authority with tasks distributed according to the demands of Accreditation.

The work of Dianne Mulcahy is helpful here (2011: 219-244). More than a process of socialization with unspecified dimensions, developing a sense of professional identity and how we locate ourselves within the professional world is informed by material elements such as the documentary infrastructure of Accreditation. Engagement with this process contributes to the interviewees' development of a sense of who they are, and what is required of them in terms of their contribution to this museum. On these grounds, I would argue that Accreditation contributes to the development of self-understanding. In this case, an understanding of museum work as preservation of existing conditions is promoted, with the task of museum managers in this case of asset transfer being limited to functional aspects. As these forms of museum management are premised on a narrative of enabling the participation of a broader set of people in deciding what the desired outcomes of museums should be, the restriction of their contributions, and the influence of Accreditation in this, designed as an aide and support, is significant.

These observations suggest a fuller account of expertize is possible through including documents and documentary infrastructures in studies of the museum, particularly when a relational materialities approach is employed to draw attention to how specific circumstances lend materials their ordering effects. This method focuses on the 'constitutive components' (Bennett 2015: 15) of this ordering potential and makes its variable outcomes visible. Such a methodological approach extends the observations of Smith (2006) where heritage management practices are seen to shore up the delegated authority of professionals. In particular, rather than suggesting documentary infrastructures are designed to promote the vested interests or form part of a strategic attempt to maintain the authority of professionals (Smith 2006: 51), this approach instead brings out the heterogeneous ways they combine with other elements present in instances of professional practice to act on the world. Viewed in this way, expertize cannot be used to explain without first being made the subject of an analytical approach that makes description of its composite parts and effects possible. 


\section{Conclusion}

This paper has called attention to the neglect of documents and documentary infrastructures in current studies of the museum. My argument was based on the identification of two tendencies within museum and heritage studies. First, relevance is often assigned to a document, generally national policy, before research is conducted. As such, practitioners are assumed to attend to policy to guide their practice such that empirical observation of the mediatory role of said document is omitted (cf. McCall 2016). Second, documents are viewed as 'carriers of content' (Prior 2008: 823) whose meaning and agency can be read off the text. This formulation ignores the variable meanings and importance assigned to documents in different settings and downplays the relationships between documents and people that are integral to organizational life. Furthermore, documentary infrastructures and the administrative protocol of the museum sector, of which Accreditation is but one example, are generally ignored, as are the processes involved in document production in and about museums. Finally, an emphasis on exhibitionmaking and documents associated with collections crowds out the other documentary forms circulating in and around museums.

To address these limitations I outlined a theoretical and methodological framework that would allow for the constitutive role of documents and documentary infrastructures to come into view, as well as making space for other types of document to be visible in research. Drawing on Bennett's extensive commentary on actor-network theory as a methodologically orientated development of Foucauldian conceptions of power, and the mutually reinforcing relation of power/knowledge, I identified three ways that these insights could be further mobilized to inform empirical work in museums. Given its emphasis on agency as something gained (or not) as an outcome of relations, and the character of these relations, as opposed to something given, the arguments made by John Law to flesh out the concept of 'relational materiality' were reviewed and their implications for methods outlined.

The case study of Accreditation's constitutive role in the context of an example of community asset transfer was used to demonstrate the analytical purchase of this approach. Accreditation was shown to give rise to various effects on someone new to museum work: configuring relationships between people; contributing to nascent orientations towards museums and museum work; constructing distinctions between professionals and their others and playing a subtle gatekeeping role between those new to museum work and the capacity to construct alternative ways of doing museums. The implications of this view for our understandings of expertize suggest the potential of the method to result in fuller and more nuanced accounts of how particular forms of museum practice are perpetuated, even in instances where the financial infrastructures associated with professionalized museum services have been removed. Given the political justification for community asset transfer rests upon empowering individuals, groups and organizations to rework the role and purpose of spaces previously managed by public bodies, the way professional protocols coordinate practice and inform decision-making in domains largely vacated by professional staff is an important observation.

This approach has implications beyond the specific object of analysis isolated in this article. The empirical material drawn upon here was an example of how documentary infrastructures influence practice, yet the paper also discussed another point of focus, the production of documents themselves, and the politics involved in this act of closure. Further, while the material on Accreditation is significant in terms of the case-specific findings, it also demonstrates why the timing of when decisions are made as to which texts, practices and so forth will become objects of analysis is important. Accreditation would not have been identified as relevant in a conventional approach where 'policy contexts' are determined at the outset (e.g. Hooper-Greenhill 2004; West and Smith 2005). In this mode, government policies are assumed to bear on museum practice in a macro/micro logic, with the correspondence between the timing of the research focus and that of a particular policy being sufficient grounds for its inclusion in a discussion of context. Starting with the practice and working outwards towards an understanding of which texts are relevant disrupts this model. Relatedly, the mediation of relationships and relations to museums and museum practice was shown to be an effect of the interplay between the textual content of Accreditation, the practices it necessitates, and their implementation by users via a process where political and financial conditions shape 
possible action. On these grounds, we start to see the value of seeing policy as a set of practices rather than merely as text. Analysing Accreditation has shown that documents and documentary infrastructures deserve more than a background or precursory role in empirical work. A methodological framework informed by actor-network theory is instructive here as it renders visible the dynamic encounters between persons, things, documents and documentary infrastructures that museums are made of and the effects of these encounters in shaping future possibilities for museums.

Received: 22 May 2018 Finally Accepted: 30 July 2018

\section{Acknowledgements}

I would like to thank the anonymous reviewers for their engagement with the paper, and Liz Stainforth for incisive comments on an earlier version of the text. Thank you also to the people who were interviewed for this research.

\section{Notes}

1 This work was supported by an Arts and Humanities Research Council Doctoral Award.

2 There is an implication of intentionality on the part of the museum that would be dismissed by actor-network theory in Bennett's use of the verb orchestrate. However, the intention of the comment is expressed earlier in the paragraph whereby the museum is the site where these heterogeneous elements come together.

3 This article draws on material from a research project where collaborative document gathering was combined with interviews. Interviewees were asked to comment on what they would do if a particular document or documentary infrastructure was no longer present. Working through this hypothetical scenario draws attention to, for example, the relationships or practices which are arranged 'around' the documentary infrastructure or the assumptions or understandings that have developed because of it.

4 Museums Association (2017) 'Museums in the UK 2017 Report', https://www. museumsassociation.org/download?id=1219029, accessed 7 April 2018.

5 At the beginning of the process of negotiating the terms of the transfer with the local authority, this individual was supported by others. Yet, by the time of the transfer, it was only the chair who remained, highlighting the drastic changes involved in asset transfer, and pointing towards the level of responsibility local authorities are willing to place on groups.

6 Arts Council England (2014a) 'Accreditation guidance: An introduction', https://www. artscouncil.org.uk/sites/default/files/download-file/FINAL_201406_Guidancelntroduction PrintFriendly.pdf accessed 19 April 2018.

7 Chair of Independent Museum Trust (April 2015) Interview with the author.

8 Chair of Independent Museum Trust (January 2016) Interview with the author.

9 Arts Council England (2014b) 'Accreditation guidance, Section one: Organisational health', accessed 19 April 2018.

10 Arts Council England (2014c) 'Accreditation guidance, Section two: Collections', http://www. artscouncil.org.uk/sites/default/files/download-file/FINAL_201406_GuidanceSection2 PrintFriendly.pdf accessed 19 April 2018.

11 Chair of Independent Museum Trust (April 2015) Interview with the author. 


\section{References}

Bennett, T. (2005) 'Civic Laboratories: Museums, Cultural Objecthood and the Governance of the Social', Cultural Studies, 19 (5) 521-547.

(2007) 'Making culture, changing society', Cultural Studies, 21 (4-5) 610-629.

(2010) 'Making and mobilising worlds: assembling and governing the other', in T. Bennett and P. Joyce (eds) Material Powers: cultural studies, history and the material turn, 190-208, London and New York: Routledge.

(2013a) Making Culture, Changing Society, London: Routledge.

(2013b) 'The "shuffle of things" and the distribution of agency', in R. Harrison, S. Byrne and A. Clarke (eds) Reassembling the Collection: Ethnographic Museums and Indigenous Agency, 3-35, Sante Fe: SAR Press.

(2015) 'Thinking (with) Museums: From Exhibitionary Complex to Governmental Assemblage', in A. Witcomb and K. Message (eds) The International Handbook of Museum Studies: Museum Theory, 3-20, Chichester: Wiley-Blackwell.

and Joyce, P. (2010) (eds) Material Powers: cultural studies, history and the material turn, London and New York: Routledge.

Byrne, S, Clarke, A, Harrison, R, and Torrence, R. (eds) (2011) Unpacking the Collection, Networks of Material and Social Agency in the Museum, New York: Springer.

Freeman, R. and Maybin, J. (2011) 'Documents, practices and policy', Evidence \& Policy: A Journal of Research, Debate and Practice, 7 (2) 155-170.

Foucault, M. (1980) Gordon, C. (ed) Power/Knowledge: Selected Interviews \& Other Writings 1972-1977, New York: Pantheon Books.

Foucault, M. [1982] (2000) 'The Subject and Power', in James D. Faubion (ed), The Essential Works of Foucault, 1954-1984, vol. 3: Power, 326-348, New York: New Press.

Gardner, J.B. (2015) 'From Idiosyncratic to Integrated: Strategic Planning for Collections', in C. McCarthy (ed) The International Handbooks of Museum Studies: Museum Practice, 203-220, Chichester: Wiley-Blackwell.

Geoghegan, H. and Hess, A. (2015) 'Object-love at the Science Museum: cultural geographies of museum storerooms', Cultural Geographies, 22 (3) 445-465.

Gosden, C. and Larson, F. (2007) Knowing Things: Exploring the Collections at the Pitt Rivers Museums 1884-1945, Oxford: Oxford University Press.

Graham, H. (2012) 'Scaling governmentality: museums, Co-production and re-calibrations of the "logic of culture", Cultural Studies, 26 (4) 565-592.

(2016) 'The "co" in co-production: Museums, community participation and Science and Technology Studies', Science Museum Group Journal, Spring: Science Museums and Research, http://journal.sciencemuseum.ac.uk/browse/issue-05/theco-in-co-production/

Hesmondhalgh, D., Oakley, K. and Nisbett, D. (2015) Culture, economy and politics: the case of New Labour, Basingstoke: Palgrave Macmillan. 
Hodder I. (2014) 'The Entanglements of Humans and Things: A Long-Term View', New Literary History, 45, 19-36.

Hooper-Greenhill, E. (2004) 'Learning from Culture: The Importance of Museums and Galleries Education Program (Phrase I) in England', Curator, 47 (4) 428-449.

Ireland, T. and Lydon, J. (2016) 'Rethinking Materiality, Memory and Identity', Public History Review, 23, 1-8.

Jones, S. and Yarrow, T. (2013) 'Crafting authenticity: An ethnography of conservation practice', Journal of Material Culture, 18 (1) 3-26.

Knell, S.J. (2012) 'The intangibility of things', in Sandra Dudley (ed.) Museum Objects, 32435, London: Routledge.

Knudsen, L. V. (2016) 'Participation at work in the museum', Museum Management and Curatorship, 31 (2) 193-211.

Larson, F., Petch, A., and Zeitlyn, D. (2007) 'Social Networks and the Creation of the Pitt Rivers Museum', Journal of Material Culture, 12 (3) 211-239.

Latour, B. (1986a) 'Visualization and cognition: thinking with eyes and hands', Knowledge and Society: Studies in the Sociology of Culture Past and Present, 6, 1-40.

(1986b) 'The powers of association', in John Law (ed.) Power, Action and Belief: $A$ new sociology of knowledge?, 264-280, London: Routledge \& Kegan Paul.

(2003) We Have Never Been Modern, Brighton: Harvester Wheatsheaf.

(2004) 'Why Has Critique Run out of Steam? From Matters of Fact to Matters of Concern', Critical Inquiry, 30, 225-248.

(2005) Reassembling the Social: An Introduction to Actor-Network-Theory, Oxford: Oxford University Press.

Law, J. (1992) Notes on the Theory of the Actor-Network: Ordering, Strategy and Heterogeneity', Systems Practice, 5 379-93.

(1994) Organising Modernity, Oxford: Blackwell.

(1999) 'After ANT: complexity, naming and topology', The Sociological Review, 47 (S1) 1-14.

(2004) After Method: Mess in Social Science Research, London and New York: Routledge.

Macdonald, S. (2002) Behind the Scenes at the Science Museum, Oxford: Berg.

(2006) 'Expanding Museum Studies: An Introduction', in S. Macdonald (ed) A Companion to Museum Studies, 1-13, Chichester: Wiley-Blackwell.

Marstine, J., Bauer, A., and Haines, C. (eds) (2013) New Directions in Museum Ethics, London and New York: Routledge.

Mason, R. (2004) 'Conflict and complement: an exploration of the discourses informing the concept of the socially inclusive museum in contemporary Britain', International Journal of Heritage Studies, 10 (1) 49-74. 
Mason, R. (2006) 'Cultural Theory and Museum Studies', in S. Macdonald (ed) A Companion to Museum Studies, 17-32, Chichester: Wiley-Blackwell.

McCarthy, C. (2015) 'Grounding Museum Studies: Introducing Practice', in C. McCarthy (ed) The International Handbooks of Museum Studies: Museum Practice, xxxvii-liv, Chichester: Wiley-Blackwell.

McCall, V. (2016) 'Exploring the Gap between Museum Policy and Practice: a Comparative analysis of Scottish, English and Welsh Local Authority Museum Services', museum \& society, 14 (1) 98-115.

McShane, I. (2016) ‘Productive Nation? Museums, Cultural Policy and Australia's Productivity Narrative', museum \& society, 14 (1) 131-145.

Mulcahy, D. (2011) 'Teacher Professional Becoming: A Practice-Based, ActorNetwork Theory Perspective', in L. Scanlon (ed) "Becoming" a Professional: an Interdisciplinary Analysis of Professional Learning, 219-244, London and New York: Springer.

Patrick, P. G. (2016) 'Visitors and alignment: actor-network theory and the ontology of informal science institutions', Museum Management and Curatorship, 32 (2) 176195.

Prior, L. (2003) Using Documents in Social Research, London, Thousand Oaks, New Delhi: Sage.

Prior, L. (2008) ‘Repositioning documents in social research’, Sociology, 42 (5) 821-836.

Riles, A. (ed) (2006) Documents: Artifacts of Modern Knowledge, Michigan: University of Michigan Press.

Sayes, E. (2014) 'Actor-network theory and methodology: Just what does it mean to say that nonhumans have agency?', Social Studies of Science, 44 (1) 134-149.

Smith, L. (2006) The Uses of Heritage, London: Routledge.

Shelton, A.A (2015) 'Museum Practice and Mediation: An Afterword', in C. McCarthy (ed) The International Handbooks of Museum Studies: Museum Practice, 203-220, Chichester: Wiley-Blackwell.

Sørensen, M.L.S., and Carman, J. (eds) (2009) Heritage Studies: Methods and Approaches, London: Routledge.

Star, S.L. (1999) 'The Ethnography of Infrastructure', American Behavioral Scientist, 43 (3) 377-391.

Turner, H. (2016) 'Introduction: special issue, critical histories of museum catalogues', Museum Anthropology, 39 (2) 102-110.

Waller, L. (2016) 'Curating actor-network theory: testing object-orientated sociology in the Science Museum', museum \& society, 14 (1) 193-206.

West, C. and Smith, C. "We Are Not A Government Poodle": Museums and Social Inclusion Under New Labour', International Journal of Cultural Policy, 11, 275-88.

Yaneva, A. (2003) 'When a bus met a museum: following artists, curators and workers in art installation', museum \& society, 1 (3) 116-131. 
*Bethany Rex is a Research Fellow in the Innovation Insights Hub, University of the Arts London and a Visiting Researcher in Media, Culture, Heritage, Newcastle University. Her current research investigates how museums and cultural organisations are adapting to the budget cuts following the 2008 financial crisis. Her specific interest is in local authority museums and how public sector values, identities and ethics are reworked in this context.

\author{
Bethany Rex \\ Research Fellow \\ Innovation Insights Hub \\ University of the Arts London \\ Central St Martins \\ Granary Building \\ 1 Granary Square \\ London \\ NIC 4AA \\ b.rex@arts.ac.uk
}

